to be hoped that such a designation will not be used; otherwise this phraseology may soon become stereotyped. The expression 'seventeen hours fifteen minutes' is accurate but long: 'seventeen hours fifteen' is a contraction analogous to 'seventeen pounds fifteen' for $£ 1715 \mathrm{~s}$. 0d. But 'seventeen fifteen' (analogous to the present 5.15 p.m., but with the now unnecessary p.m. dropped) should be quite sufficient. At the exact hour, 17 hours can be used as simpler than 17.00 .

\section{Origin of Tektites}

The suggestion first made in NATURE (131, 117 ; 1933) by Dr. L. J. Spencer that tektites have been formed by the fusion of terrestrial rocks by the fall of very large meteorites has given rise to an interesting discussion, but, being unexpectedly novel, it has not met with general acceptance. Prof. F. E. Suess of Vienna, in whose classical paper of 1900 the name tektite was introduced and the meteoritic theory first proposed, has returned to the subject and he gives a recent review in Die Naturwissenschaften (21, 857, Dec. 8, 1933). Here, and in a private letter, he admits that the Darwin glass of Tasmania may have been formed by the fusion of terrestrial material. Some of the silica-glass from the meteorite craters at Wabar in Arabia is, in fact, exactly like Darwin glass in every respect, and at both places the material is present in thousands of tons. But from Tasmania no meteoric iron or craters have been recorded. For other tektites (australites, billitonites, moldavites and 'indochinites'), Prof. Suess still holds to the meteoritic theory. He points out that they have a much wider distribution than the silica-glass found around meteorite craters, and also that they usually bear no relation in chemical composition to the underlying rocks. The same arguments are also put forward in a letter to the Editor from Mr. T. HodgeSmith, of the Australian Museum, Sydney, who has given an account of the tektites recently found in the Philippine Islands. These arguments, however, overlook the fact that tektites are usually found in alluvial deposits and that they are often waterworn and corroded, indicating that they have been transported from their place of origin. In the case of australites found scattered on the surface of the ground over wide areas, it is conceivable that they have been transported by the natives.

\section{The 200 inch Reflector}

Ix was reported in the Times of March 27 that an accident had occurred during the pouring of the twenty tons of glass into the mould of the two hundred inch mirror for the new reflector for the California Institute of Technology. Part of the mould came loose and floated to the top of the molten glass. As soon as the pouring was completed, the cores were fished out of the molten mass. According to a message issued by Science Service, Dr. Hostetter, who was in charge of the operations, said that this mishap would not affect the success of the mirror, which has now been set aside to cool very slowly. After the months of cooling have elapsed, it will take several years to grind the surface of the mirror. Our readers will join with us in expressing the hope that it will be found that the incident of the break-up of the mould will not have spoilt the present pouring of glass.

\section{Refrigeration Exhibition at the Science Museum}

Sixtr years ago mechanical refrigeration was just coming into existence, and yet to-day it is an essential part of everyday life, not only in its well-known application to the transport and storage (including domestic storage) of perishable foodstuffs, but also in many of the industries upon which Great Britain depends. Of its lesser-known uses mention may be made of the manufacture of bread, biscuits, chocolate, margarine, artificial silk stockings and cinematograph films, the brewing of beer, the curing of bacon, the refining of oil and the sinking of mine shafts and wells. These are a few of about three hundred industries in which its use is either essential or in which it improves the quality of the product. With the object of illustrating the part played by refrigeration, and of showing the public the principles on which the several types of machines operate, a special exhibition has been arranged at the Science Museum, South Kensington, and will remain open until the end of August. It consists mainly of models, working exhibits and demonstrations. The exhibits have been supplied by the manufacturers and users of refrigerating machinery and the Museum has had the wholehearted co-operation of the British Association of Refrigeration, the National Physical Laboratory and the Low Temperature Research Station. A small Handbook has been prepared and will be on sale at the price of $6 d$. (by post $7 d$.): copies may also be obtained from H.M. Stationery Office. Anyone who is interested in the subject may obtain from this Handbook in a concise form an idea of the modern science and practice of mechanical refrigeration : the handbook also contains a brief outline of its historical development. In addition, a bibliography on refrigeration has been prepared in the Science Museum Library and will also be on sale.

\section{Models of Tidal Estuaries}

Ar the Friday evening discourse held at the Royal Institution on April 13, Prof. A. H. Gibson discussed "Tidal Estuaries: Forecasting by Model Experiments". During recent years much work has been done on models reproducing the flow of water over weirs, through sluice gates, etc., and it has been found that, if suitable precautions are taken, the model results give a reliable indication of the behaviour of the original. River flow models are now being extensively used to investigate the erosion and deposition of bed materials and the effect of works designed to improve the navigable channel. The technique of such investigations is not yet fully developed, different methods being used in different laboratories. Chronologically, models of tidal estuaries were used before those of uni-flow rivers, the first tidal models (of the Mersey Estuary) having been constructed by Osborne Reynolds in 1885 . 